\title{
Every Moment Matters: Study of Employee Engagement at Radisson Hotel Group, Nagpur
}

\author{
${ }^{1}$ Mr. Tejosh Kumar Saini, ${ }^{2}$ Dr. Ruchi Sao \\ ${ }^{1}$ Senior HR Manager, Radisson Hotel Group, Nagpur \\ ${ }^{2}$ Assistant Professor, Shri Ramdeobaba College of Engineering and Management, Nagpur \\ Email:hrm@rdnagpur.com,saorn@rknec.edu
}

Received: $20^{\text {th }}$ September 2018, Accepted: $11^{\text {th }}$ October 2018, Published: $31^{\text {st }}$ October 2018

\begin{abstract}
The term 'engagement' is one of the most talked terms in the field of human resource management. Surely this reflects its importance as a tool for effective management of employees, however at the same time this also reflects the complexities that it involves.

A lot of surveys have been conducted to ascertain the better way of engaging employees, be it through recommendation of changes in technology or policy or organisation's mission or change in internal way of working. However, the more the research and new practices we come across and apply every day the more challenges we face particularly in Indian hospitality sector wherein retaining good employees for long and holding them to grow with the organisation is often a challenge.

This paper examines the methods adopted at Radisson Blu Hotel Group (RDN), Nagpur in keeping score of its employee engagement at high level, resulting in business performance.

The paper would discuss the various approaches adopted, be it:

- Bringing a culture which intrinsically develops employee engagement;

- Instant recognition of a good work;

- Applying forced measures to secure good health of employees;

- Imbedding fun as part of work;

- Ensuring process oriented employee career growth;

- Managing work life balance;

- Developing employees' basic skills as per need of the society;

- Strategizing engagements activities as per tenure in organisation.

Thus, the paper tries to find out the success or lack of it in any of the activities adopted at this work place and tries to derive a better way of implementing all this methods.
\end{abstract}

\section{Keywords}

Employee Development, Employee Engagement, Organization Culture

\section{Introduction:}

Simon Sinek in his book on "Start with why" aptly said, "When people are financially invested, they want a return. When people are emotionally invested, they want to contribute."

The concept of employee engagement has been used synonymously with employee happiness or job satisfaction. However, it is actually the emotional connect and attachment of an employee towards his job and organization. The concept of employee engagement states that the employee will always be proactive, take the job beyond job description and act with full responsibility and accountability.

Radisson Blu Hotel Group (RDN), takes intense efforts in hiring human resources by applying appropriate checks in recruitment and selection process to ensure they get near to perfect candidates as per organisation's requirement. While as a recruiter when we apply all the checks to ensure right availability, don't forget that the candidate is also applying the checks whatever available to him/her to select employer of his choice. Now after such a careful selection when a candidate decided to join a particular organisation it exhibits his contentment and enthusiasm to work with the company and to gain benefits from his work with the organisation.

And if this stands true, then it shows that when an employee joins the organisation he remains fully engaged with the organisation and it is only after elapsing of time that he may start getting disengaged with the organisation.

Hence, the need is to avoid disengagement among employees while boosting the existing engagement practices. One of the reasons that employees starts getting disengaged is the leader's action or inaction related to employees work and efforts. When employees feel that they are not valued as a resource in the organisation they tend to do bare minimum of work required for survival and the ideas to bring something new at work get reduced. Though such employee might be happy doing his job and getting paid for it however certainly not engaged with the organisation. 
There are various models of employee engagement such as Sarah Cook (WIFI model) and Gallup model. However, the Aon Hewitt gives a clear association of employee engagement initiatives with business outcomes with respect to talent, internal business process, customer and finance. Broadly, there are three categories of employees with respect to engagement. They are:

- Engaged Employees:

These employees adhere to the rules and regulations of the organization and follows the organization culture. They would beyond the call of their job description and role.

- Not Engaged Employees:

These employees would stay in the organization and just complete the job description without criticizing or complaining. However, they would not be engaged in their work and with the organization as compared to the engaged ones.

- Actively Disengaged Employees

These employees would ensure to act as a critic and would express their unhappiness with respect to the working and environment of the organization. They will not be engaged and would express and conduct activities related to disengagement at workplace.

The various competencies that RDN tries to develop in their leaders are discussed briefly as under:

- Emphasis on Sincere and Immediate Recognition:

RDN employs pre-set programmes for employees' immediate recognition. Every employee at leadership position can and should apply these practices in order to maintain a healthy team spirit, and keep the scores of application of such programmes at competitive level vis a vis other departments at RDN. The practises are in line with the motto of RDN, "Every Moments Matters'. As different people like to be recognised differently, the hotel has set different recognition programmes to satisfy employee's engagement needs.

- Importance to Human Resources:

The idea here is to make employees comfortable at their work environment to enable them to produce their best for work place. RDN lays down a lot of emphasis to its employees by organizing various events and taking care of their needs.

- Act as Mentor to his/her Team:

Employees bring more than their physical presence to work; they bring their life history and their stories and experiences. As a mentor the team HR and other department leaders at Radisson Blu gain an understanding of their past and present, and their goals for the future. It also helps employees know that we care about them.

- Act towards Team Development:

The goal is to appreciate but also share opportunity areas with employees since it is key driver of employee engagement.

- Treating employees as more than resources:

Striking a healthy balance between work-life and personal-life is incredibly important and something everyone should strive to achieve. With this as goal all the managers ensures that staff should not keep working on same shift for very long. As ours is 24/7 running operations managing flexibility on working hours becomes more important.

\section{Material and Methods}

The study is a qualitative study in which in depth interview method was used to investigate about the HR policies and various employee engagement initiatives taken by the hotel. The Aon Hewitt Employee Engagement Model is used to assess the level of engagement. The initiatives taken are directly linked to the business of the hotel resulting into increased profits as compared to the previous years. The mission of the hotel is to treat and keep the employee well which will result in fulfilment of responsibilities at job in the best possible way. The highly productive employees in turn help the customers and give them the best ever experience and every moment of the customer spent in the hotel is worth it. Customer retention and happiness results in loyalty thereby reflecting it at the financial front. The objectives of the study are:

- To identify the employee engagement initiatives at RDN

- To associate the initiatives with the Aon Hewitt Model of Employee Engagement

On the basis of Aon Hewitt Model, the employee engagement drivers at RDN are: emphasis on sincere and immediate recognition, importance to human resources, act as mentor to his / her team, act towards team development and treating employees as more than resources. This results in employee engagement outcomes of say, stay and strive at RDN. The employees say positive about the organization, stay in the organization and strive hard to give their best performance at the hotel. Thus, resulting into business outcomes in the form of: 
- Talent retention

- High quality of internal processes

- Customer growth and retention

- $\quad$ Financial strength of the hotel

For having effective engagement practices it is required to have effective leadership at work. This style of leadership is exercised by the General Manager of the Hotel with the help of the entire HR department.

\section{Results and Discussion}

Since a long time, RDN has put the employees as top priority and in order to cater to their needs have got amazing engagement initiatives which would be discussed in detail.

\section{- Emphasis on Sincere and Immediate Recognition:}

○ Poker Chips: The employees at leadership position are provided with small booklet of tokens. Whenever a leader spots any activity by any junior staff which is worth admiring and recognising, s/he can immediately bestow any no of tokens, as appropriate, to the junior staff. The collection of such tokens gets benefits to staff like: on 5 such tokens an employee can avail a cake from the Hotel. For 10 tokens a movie ticket for two is sponsored by Hotel for such employee. On 15 tokens the employee can reimburse the petrol for his/her vehicle upto the extent of Rs. 600, and on 20 token a dinner in Hotel's restaurant with friends and family is offered to the employees.

o Due Recognition to Time Spent with RDN: As per standard all employees of the Hotel are provided with the name tags that they ought to wear at all the times on the duty. As a best practice at Hotel, a mark coloured differentiation is made on these name tags of employees. Thus Hotel ensured that it valued the longevity of the employees.

- Immediate Pasting of Employee's photo on Notice Board whenever they get a Good Comment from Hotel Guests: Time of recognition matters. At RDN, we ensure to praise the employees by pasting their picture on notice board as soon as we get a good/positive comment from the Hotel guests.

\section{- Importance to Human Resources:}

- On Time Salary: RDN ensures that employees get salary on very $1^{\text {st }}$ day of month. However this practice is not limited to Hotel's employees only. We confirmed that all the contractual employees should also get salary on the first day of month. This is one of the primary condition to hire a contractor for outsourced activities.

○ Town Hall Meetings: Grow your people and people grow you. With this motto regular Town hall meeting is inherent practices of work environment RDN. This aims at downloading all the staff with Hotel's performance and future challenge and soliciting suggestion for further improvements at work area from all employees.

- Hallabol: It is with its human resources a Hotel achieves the happiness for its guests. Only happy employees can make their guests happy. Considering this, RDN organises a month long sports and cultural activities specifically in the month of May. This gives vast platform to all the employees wherein they are free to show their innovation and talent on the one side while enjoying the participation in sports activities on the other. During the entire month the Hotel premises becomes more like a youth festival forum and that is the idea of such events.

- Sparkling Saturday: To bring more fun to workplace, every Saturday the employees get the chance for participating in recreation activities facilitated by HR department. Be it competitive activities or indoor games or simple movie shows.

- Act as Mentor to Team:

o HR Connect: All the HR personnel are given target to meet at least 10 employees in a month on their shift. The purpose of the meeting is to have a general chatting with the employee and to make them come out with work or personal matters which employee wish to share with. These employees become permanent account of that HR personnel and remains responsible till the end of the employment cycle in the Hotel.

o Drop Service to all Employees irrespective of Gender: Security of its employees is top most priority for RDN. Though as per law we are required to provide vehicle to drop facility to our female employees, this facility is extended to all employees of the Hotel.

- Surprise Home Visit and Gifts to Spouse on Employees Anniversary: The HR department or there representative has adopted the practice of visiting the spouse of married employee who are working at leadership role to congratulate him/her on special day. The idea is to participate in employee's happiness also besides handling their worries. 
- Prohibition on Consuming Tobacco: RDN has laid down strictest measures to prohibit consumption of any kind of tobacco at work place. Also to keep the environment clean as a policy no candidate is allowed to join the organisation until he produces fit dental certificate.

- $\quad$ Act Towards Team Development:

o Programme for Inter Department Transfer: RDN provides the opportunity to all employees to apply for getting them transferred to other department from their current one.

○ Grow Your People and People Grow You: A well designed employee succession programme called HIPO is in place to ensure deserving employees gets appropriate platform for career growth. The potential employees are given set targets to achieve within prescribed time limit. The performance of the employees entitles them to be considering for Job Enlargement at same or other units.

- Computer Literacy Programme: RDN had conducted a onetime exercise for making its employees literate in computer basics. The exercise was primarily focussed on outsourced third party employees and aimed to create sense of belongingness among all employees.

○ English Speaking Classes: For all employees, outside tutor was engaged to organise English speaking classes for which $50 \%$ fees was sponsored by the Hotel.

\section{Conclusion}

RDN thrives on its belief i.e. "Every Moment Matters". To inculcate this in its culture the efforts are directed towards developing above mentioned competencies in all those employees who are working at leadership position at RDN.

As it is been claimed that staff does not leave any organisation, they leave their supervisor or boss. It was necessary to make the leaders understand the importance of their behaviour and conduct towards their team. By valuing each moment a staff spends at work, the leaders can make the moments memorable for employees.

The result of above mentioned engagements practices are manifold. In past three years since when these practices are executed at RDN, the attrition count is reduced from $5 \%$ to $3 \%$, and on business front RDN has seen a double digit growth in revenues.

However not all the practices were successful, like, bifurcation of name tags, prohibition on tobacco consumption and English speaking classes does not had considerable impact on employees motivation level. However by other means RDN assured to its employees that every moment spent at RDN will be valued and considered fruitful for them.

\section{References}

1. Popli, S., \& Rizvi, I. A. (2016). Drivers of employee engagement: The role of leadership style. Global Business Review, 17(4), 965-979

2. Brown, D., \& Reilly, P. (2013). Reward and engagement: The new realities. Compensation \& Benefits Review, 45(3), 145-157

3. Memon, M. A., Salleh, R., \& Baharom, M. N. R. (2016). The link between training satisfaction, work engagement and turnover intention. European Journal of Training and Development, 40(6), 407-429

4. Pandita, D., \& Bedarkar, M. (2015). Factors affecting employee performance: A conceptual study on the drivers of employee engagement. Prabandhan: Indian Journal of Management, 8(7), 29-40

5. McBain, R. (2007). The practice of engagement: Research into current employee engagement practice. Strategic HR review, 6(6), 16-19

6. http://www.aon.com/2018-global-employee-engagement-trends/index.html 